\title{
Attenuation of copaiba oil in hepatic damage in rats ${ }^{1}$
}

\author{
Marcus Vinicius Henriques Brito ${ }^{\mathrm{I}}$, Felipe D’Almeida Costa ${ }^{\mathrm{II}}$, Diego Matos de Vasconcelos ${ }^{\mathrm{III}}$, Lauro Augusto Veloso Costa ${ }^{\mathrm{IV}}$, \\ Edson Yuzur Yasojimav, Renan Kleber Costa Teixeiravi, Vitor Nagai Yamaki ${ }^{\text {VII }}$
}

DOI: http://dx.doi.org/10.1590/S0102-86502014001900002

IPhD, Full Professor, Head, Department of Integrate Health, Medical School, Para State University (UEPA), Belem-PA, Brazil. Scientific and intellectual content of the study and critical and final revision.

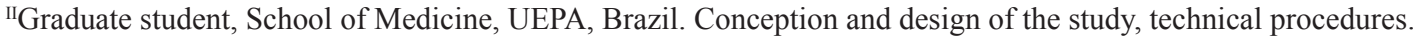

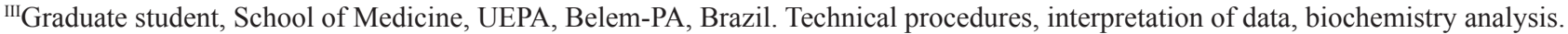

${ }^{\mathrm{V}} \mathrm{G}$ Graduate student, School of Medicine, UEPA, Belem-PA, Brazil. Technical procedures, Interpretation of data, critical revision.

${ }^{\vee} \mathrm{PhD}$, Associate Professor, Medical School, UEPA, Belem-PA, Brazil. Conception and design of the study, manuscript writing, critical revision.

${ }^{\mathrm{VI}}$ Graduate student, School of Medicine, UEPA, Belem-PA, Brazil. Grant from Institutional Program for Scientific Initiation (PIBIC) of the National Council of Scientific and Technological Development (CNPq), Ministry of Science, Technology and Inovation, Brazil. Technical procedures, care of animals.

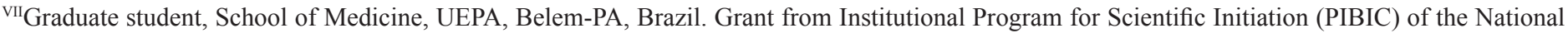
Council of Scientific and Technological Development (CNPq), Ministry of Science, Technology and Inovation, Brazil. Biostatistics analysis, care of animals, manuscript preparation.

\section{ABSTRACT}

PURPOSE: To investigate the copaiba oil on the hepatic damage induced by acetaminophen, comparing against corn oil.

METHODS: Fifty four rats were distributed into nine study groups $(\mathrm{N}=6)$ : control group, that didn't receive the acetaminophen; Acetaminophen Group, that only received the acetaminophen; Prophylactic Copaiba Group 1, that received copaiba oil two hours before the acetaminophen; Prophylactic Copaiba Group 7, that received copaiba oil seven days, once by day, before the acetaminophen; Therapy Copaiba Group, that received the copaiba oil two hours after the acetaminophen, the corn's groups were similar than copaiba oil groups; and N-Acetyl-Cysteine Group, that received the N-Acetyl-Cysteine two hours after the acetaminophen. Euthanasia was performed after 24 hours. The serum levels transaminases, bilirubin and canalicular enzymes were analyzed.

RESULTS: The prophylactic copaiba group 7, therapy copaiba group and N-Acetyl-Cysteine Group showed amounts of AST and ALT similar to the control group; and the prophylactic copaiba group 1 and corn's groups showed similar levels to the acetaminophen group. There was no significant difference between the groups regarding the amount of alkaline phosphatase and $\gamma$ GT ( $>0.05$ ). The therapy copaiba group showed the highest levels of total bilirubin and was statistically different from the other groups $(\mathrm{p}<0.01)$.

CONCLUSIONS: Copaiba oil administered prophylactically for seven days and therapeutically 2 hours after the acetaminophen acute intoxication offered a potential hepato protection against paracetamol-induced hepatic damage, normalizing the biochemical parameters similarly to N-Acetyl-Cysteine, and the treatment with corn oil shows no effect on the liver damage.

Key words: Plant Oils. Hepatitis. Liver. Acetaminophen. Rats. 


\section{Introduction}

Acute liver failure (ALF) is characterized as a syndrome with sudden progression and severe hepatocellular dysfunction ${ }^{1}$. The commitment of liver function leads to failure in physiological processes during homeostasis regulation, such as synthesis of plasma proteins, metabolism of lipids, carbohydrates and proteins, as well as performing inactivation of medications and toxic $\operatorname{drugs}^{2,3}$.

This syndrome has multiple etiologies, such as viral hepatitis, poisoning, ischemic events and induced by drugs ${ }^{4}$. However, the most important cause is related to overdose of acetaminophen, analgesic and antipyretic widely and indiscriminately used in the word. In the United States nearly 100.000 cases of suicide attempt occur per year by ingestion of acetaminophen, and the unintentional acetaminophen overdose is increasing every year as well, mainly in people with previous liver disease, in use of anticonvulsants, chronic alcoholics and in children $^{5-7}$.

There are several studies that search for treatments and antidotes for acute liver toxicity. The use of herbal has shown promising results, when compared with $\mathrm{N}$-acetyl-cysteine (gold standard treatment for acetaminophen's hepatotoxicity), suggesting an alternative handling for the toxic liver disorder ${ }^{8-12}$.

There are considerable amount of herbal among several species in amazon forest, amongst which copaiba oil stands out by scientifically comproved effects in wound healing, antiinflammatory and hepato protective effects ${ }^{13-15}$. In our previous study, copaiba oil showed a protective effect against liver injury; however it was not possible to identify the factors that led to decreased damage and a more detailed understand about the histopathological changes in damaged liver ${ }^{16}$. Thus, it was necessary to expand the study to elucidate some questions about the mechanism of this hepatoprotective effect. Therefore, the objective of this study is to investigate the copaiba oil in the acetaminophen hepatic liver failure induced, comparing against corn oil.

\section{Methods}

Approved by the Ethics Committee in the Use of Animals of the State University of Para (UEPA), protocol 08/07.This study used the copaiba oil species Copaiffera officinalis, supplied by Brazilian Agricultural Research Corporation (EMBRAPA) as crude oil, previously submitted to a physicochemical analyze to define its composition. The corn oil was obtained from a conventional commercial source.
Fifty four male Wistar rats (Rattus norvegicus) were used, weighing between 200 - 250 grams, provided from the animal colony of the Instituto Evandro Chagas and transferred to the animal colony of the Experimental Surgery Laboratory of UEPA, kept in a controlled environment, with food and water ad libitum, where they stayed for 15 days before the beginning of the experiment for adaptation. The animals were randomized distributed into six study groups, with six animals each:

Control Group (CG): The animals were used as normal standard for biochemical and histological analysis;

Acetaminophen Group (AG): The animals received a single dose of acetaminophen;

Prophylactic Copaiba Group 1 (PCG1): The animals received copaiba oil, once, two hours before receiving the acetaminophen dose;

Prophylactic Copaiba Group 7 (PCG7): The animals received copaiba oil, once, seven days before receiving the acetaminophen dose;

Therapy Copaiba Group (TCG): The animals received copaiba oil two hours after receiving the acetaminophen dose;

Prophylactic Corn Group 1 (PCOG1): The animals received corn oil, once, two hours before receiving the acetaminophen dose;

Prophylactic Corn Group 7 (PCOG7): The animals received corn oil, once, seven days before receiving the acetaminophen dose;

Therapy Corn Group (TCOG): The animals received corn oil two hours after receiving the acetaminophen dose;

N-Acetyl-Cysteine Group (NG): The animals received $\mathrm{N}$-Acetyl-Cysteine, two hours after receiving the acetaminophen dose.

Copaiba oil was administered by gavage at a dose of $0.63 \mathrm{~mL} / \mathrm{kg}$ in group PCG7 and $3.8 \mathrm{~mL} / \mathrm{kg}$ in groups PCG1 and TCG. The acetaminophen and $\mathrm{N}$-acetyl-cysteine were obtained with a concentration of $400 \mathrm{mg} / \mathrm{mL}$ and $300 \mathrm{mg} / \mathrm{mL}$, respectively. The acetaminophen and $\mathrm{N}$-acetyl-cysteine were administered by gavage at a dose of $2 \mathrm{~g} / \mathrm{kg}$ and $1.2 \mathrm{~g} / \mathrm{kg}$, respectively ${ }^{9,11}$.

After 24 hours from the acetaminophen administration, a xyphopubic laparotomy was performed to collect $5 \mathrm{ml}$ from inferior vena cava for biochemical measurement of aspartate aminotransferase (AST), alanine aminotransferase (ALT), alkaline phosphatase, gamma glutamyl traspeptidase ( $(\mathrm{GT})$, total bilirubin (TB) and its fractions, Direct (DB) and indirect (IB).

ANOVA test was used to compare the biochemical results, adopting a 5\% significance level to reject the nullity hypothesis. 


\section{Results}

The mean serum levels of AST and ALT in each group are shown in Table1. On these significant differences between the CG and the groups AG and PCG1 and all groups treated with corn oil, $(\mathrm{p}<0.01)$ also was no significant difference between the AG and the groups PCG7, GCT and NG.

TABLE 1 - Mean and standard deviation of serum AST and ALT according to the groups.

\begin{tabular}{ccc}
\hline Group & AST & ALT \\
\hline CG & $131.66 \pm 17.71$ & $74.16 \pm 15.18$ \\
AG $^{*}$ & $373.00 \pm 103.91$ & $311.00 \pm 137.77$ \\
PCG1 $^{*}$ & $303.00 \pm 214.85$ & $226.83 \pm 159.90$ \\
PCG7 $^{\#}$ & $225.00 \pm 95.29$ & $164.33 \pm 62.05$ \\
TCG $^{\#}$ & $198.33 \pm 91.99$ & $168.16 \pm 41.84$ \\
PCOG1 $^{*}$ & $333.50 \pm 79.97$ & $322.00 \pm 164.29$ \\
PCOG7 $^{*}$ & $263.66 \pm 100.73$ & $253.00 \pm 127.19$ \\
TCOG $^{*}$ & $424.33 \pm 103.50$ & $403.50 \pm 102.99$ \\
NG $^{\#}$ & $175.33 \pm 97.08$ & $104.50 \pm 73.90$ \\
\hline
\end{tabular}

Source: Protocol search

$* \mathrm{p}<0.01$ relative to $\mathrm{CG}$ (ANOVA)

$\# \mathrm{p}<0.01$ relative to $\mathrm{AG}$ (ANOVA)

Regarding the measurement of alkaline phosphatase and $\gamma$ GT (Table 2), no significant difference between groups was showed. Regarding total bilirubin and fractions (Table 3 ) there was a statistical difference $(\mathrm{p}<0.01)$ between TCG and all other groups in the dosage of total bilirubin and indirect, but there was no statistical difference between the groups regarding the estimation of direct bilirubin.

TABLE 2 - Mean and standard deviation of serum alkaline phosphatase and $\gamma$ GT according to the groups.

\begin{tabular}{ccc}
\hline Group & alkalinephosphatase & $\gamma \mathrm{GT}$ \\
\hline CG & $150.33 \pm 88.14$ & $6.83 \pm 1.83$ \\
AG & $195.16 \pm 58.43$ & $7.16 \pm 1.60$ \\
PCG1 & $145.66 \pm 30.91$ & $7.83 \pm 2.40$ \\
PCG7 & $181.50 \pm 29.04$ & $6.00 \pm 1.26$ \\
TCG & $112.50 \pm 65.49$ & $5.66 \pm 1.03$ \\
PCOG1 & $210.16 \pm 27.66$ & $6.66 \pm 1.86$ \\
PCOG7 & $182.16 \pm 34.10$ & $5.50 \pm 1.22$ \\
TCOG & $262.50 \pm 16.22$ & $5.66 \pm 1.36$ \\
NG & $145.00 \pm 52.82$ & $7.50 \pm 1.87$ \\
\hline
\end{tabular}

Source: Protocol search

$\mathrm{p}>0.05$ (ANOVA)
TABLE 3 - Mean and standard deviation of serum total bilirubin and fractions according to the groups.

\begin{tabular}{cccc}
\hline Group & Total bilirubin* & Direct bilirubin & Indirect bilirubin \\
\hline CG & $0.0783 \pm 0.04$ & $0.0283 \pm 0.01$ & $0.0500 \pm 0.02$ \\
AG & $0.2133 \pm 0.11$ & $0.0433 \pm 0.02$ & $0.1700 \pm 0.11$ \\
PCG1 & $0.2567 \pm 0.09$ & $0.0617 \pm 0.02$ & $0.1950 \pm 0.09$ \\
PCG7 & $0.1633 \pm 0.08$ & $0.0450 \pm 0.02$ & $0.1183 \pm 0.06$ \\
TCG & $0.5100 \pm 0.46$ & $0.1033 \pm 0.12$ & $0.4067 \pm 0.35$ \\
PCOG1 & $0.2417 \pm 0.13$ & $0.0617 \pm 0.03$ & $0.1867 \pm 0.12$ \\
PCOG7 & $0.2033 \pm 0.06$ & $0.0633 \pm 0.03$ & $0.1400 \pm 0.04$ \\
TCOG & $0.2217 \pm 0.13$ & $0.0750 \pm 0.05$ & $0.1467 \pm 0.08$ \\
NG & $0.1167 \pm 0.04$ & $0.0385 \pm 0.03$ & $0.0733 \pm 0.03$ \\
\hline
\end{tabular}

Source: Protocol search

$* \mathrm{p}<0.01$ TCG relative to outhers groups (ANOVA)

\section{Discussion}

The mechanism of hepatotoxicity caused by acetaminophen is unknown, however, there is a massive production of oxygen free radicals and a direct cytotoxic effect involved in the pathogenesis of this lesion, with a consequent necrosis and apoptosis of the hepatocytes ${ }^{17,18}$.

In our previous study ${ }^{16}$ it was proposed that copaiba oil decreased levels of liver injury induced by acetaminophen, reinforcing the herbal anti-inflammatory effect. Nevertheless, to ensure the safety and the effectiveness of this oil its necessary to know detailed mechanism of this herbal, before applying it in large animal models.

Corn oil is a substance containing similar features of viscosity and density compared to copaiba oil and recently has been considered as a control substance in researches involving copaiba oil ${ }^{19}$. Furthermore, it is known that corn oil has significant levels of omega- 6 and some studies suggest that diets rich in omega- 6 provided improvement in liver regeneration ${ }^{20}$. Thus, we included this oil to evaluate if this substance shows improvement liver regeneration or if it is a standard of control substance to experiments with copaiba.

The use of the copaiba oil's dose of $3.8 \mathrm{ml} / \mathrm{Kg}$, used in PCG1 and TCG, was based on the total amount of oil administered in PCG7 and toxicity studies on copaiba oil. It was an attempt to match the dose offered in all groups that received copaiba. In addition, the same dose of corn oil was given to simulate the amount of lipids administered to the animals.

According to hepatic enzymes, only PCG7 and TCG groups presented reduced levels in ALF. The absence of a positive outcome in groups treated with corn oil reveals that 
injury attenuation by copaiba oil was not due to stimulation of liver regeneration ${ }^{9,11,20}$. This evidence suggest the hypothesis that Copaiba's mechanism takes place reducing free radicals in tissue by herbal anti-inflammatory properties, previously described by Noguchi et al. ${ }^{15}$, suggesting an actual hepato protective effect of this oil.

Another hypothesis that suggests the attenuation in liver tissue damage could be justified by a predominant lipid diet in both prophylactic groups. This is supported due to lipid diet induces a rising in free radicals synthesis, leading the organism to be prepared with antioxidant defenses, such as a preconditioning status $^{20}$. However, lipids concentrations are similar in groups treated seven days before with both oils, although decreases in aminotransferases levels was not observed in groups treated prophylactically with corn oil.

The alkaline phosphatase and $r$ GT serum levels usually raise when colestatic liver events occurs. In toxic hepatitis induced by drugs these biochemical markers generally show values within the normal range, whereas the acetaminophen's cytotoxic effect ultimately generates a cytological damage in a physiological phase before the bilirubin excretion step ${ }^{21,22}$. Studies using fat-rich substances, at high doses, showed that these substances raise the serum levels of those enzymes, whereas the high-fat ends up slowing down the bile excretion. This effect probably did not occur in this experiment due to the short period that the animals were exposed to the substances and the low doses administered as well.

Therapy copaiba group expressed a higher bilirubin level when compared to other experimental groups, though this increase due to unconjugated bilirubin, showing that copaiba could preserve a higher amount of hepatocytes, however with reduction in cells function ${ }^{8-11}$. Furthermore, rising in bilirubin levels cannot be influenced by increased in lipids consumption, as TCOG group did not show statistical difference.

The copaiba oil attenuated the liver damage caused by acetaminophen, but this protective effect needs further investigation to comprehend the mechanism and main active principle related to this functions. Therefore, additional experiments using oxidative stress analysis and attempts to isolate active principles are extremely important to implementation of this herbal.

\section{Conclusions}

Copaiba oil administered prophylactically for seven days and therapeutically 2 hours after the acetaminophen acute intoxication offered a potencial hepatoprotection against paracetamol-induced hepatic damage, normalizing the biochemical parameters similarly to N-Acetyl-Cysteine, and the treatment with corn oil shows no effect on the liver damage. However, the treated with copaiba therapeutically showed increases in bilirubin, at the cost of its indirect fraction.

\section{References}

1. Gulmez SE,Larrey D,Pageaux GP, Lignot S, Lassalle R, Jove J, Gatta A, McCormick PA, Metselaar HJ, Monteiro E, Thorburn D, Bernal W, Vafiadis IZ, Vries C, Gutthann SP, Sturkenboom M, Benichou J, Montastruc J, Horszmans Y, Salvo F, Hamoud F, Micon S, Perroteau $\mathrm{CD}$, Blin P, Moore N. Transplantation for acute liver failure in patients exposed to NSAIDs or paracetamol (acetaminophen). Drug Safety. 2013 Feb;36(2):135-44. doi: 10.1007/s40264-012-0013-7.

2. Alberti LR, Veloso DFM, Vasconcellos LS, Petroianu A. Is there a relationship between lipids metabolism and splenic surgeries? Acta Cir Bras. 2012 Nov;27(11):751-6. doi: 10.1590/S010286502012001100002.

3. Potthoff MJ, Inagaki $T$, Satapati S, Ding X, He T, Goetz R, Mohammadi M, Finck BN, Mangeldorf DJ, Klçiewer SA, Burgess SC. FGF21 induces PGC- $1 \alpha$ and regulates carbohydrate and fatty acid metabolism during the adaptive starvation response. Proc Natl Acad Sci USA. 2009 Jun;106:10853-8. doi: 10.1073/ pnas.0904187106.

4. Bernal W, Auzinger G, Dhawan A, Wendon J. Acute liver failure. Lancet. 2010 Jul;376(9736):190-201. doi: 10.1016/S01406736(10)60274-7.

5. Rothman KJ, Lanza LL. Estimated risks of fatal events associated with acetaminophen, ibuprofen, and naproxen sodium used for analgesia. Adv Pharmacol Epidem Drug Safety. 2013;2:1. doi: 0.4172/2167-1052.1000124.

6. Leonis MA, Alonso EM, Im K, Belle SH, Squires RH. Chronic acetaminophen exposure in pediatric acute liver failure. Pediatrics. 2013 March;131(3): 40-6. doi: 10.1542/peds.2011-3035.

7. Doyon S, Klein-Schawartz W, Lee S, Beuhler MC. Fatalities involving acetaminophen combination products reported to United States poison centers. Clin Toxicol. 2013 Dec;51(10):941-8. doi: 10.3109/15563650.2013.848282.

8. Olaleye MT, Akinmoladun AC, Ogunboye AA, Akindahunsi AA. Antioxidant activity and hepatoprotective property of leaf extracts of Boerhaavia diffusa Linn against acetaminophen-induced liver damage in rats. Food Chem Toxicol. 2010 Aug;48(8-9):2200-5. doi: 10.1016/j.fct.2010.05.047.

9. Chen M, Wang T, Jiang ZZ, Shan C, Wang H, Wu MJ, Zhang S, Zhang Y, Zhang LY. Anti-inflammatory and hepatoprotective effects of total flavonoid C-glycosides from Abrus mollis extracts. Chin J Nat Med. 2014 Aug;12(8):590-8. doi: 10.1016/S18755364(14)60090-X.

10. Hemamalini1K, Preethil B, Bhargav A, Vasireddy U. Hepatoprotective activity of Kigelia africana and Anogeissus accuminata against acetaminophen induced hepatotoxicity in rats. Int J Pharmacol Biomed Res. 2012 Sep;3(3):152-6.

11. Kangralkar VA, Patil SD, Bandivadekar RM, Nandagaon VS, Burli SC. Hepatoprotective activity of Feronia elephantum fruit extract against acetaminophen induced hepatic damage in Wistar rats. Int $\mathrm{J}$ Pharmaceutical Appl. 2010 Jan;1(1):46-9.

12. Subramanian M, Balakrishnan S, Chinnaiyan SK, Sekar VK, Chandu AN. Hepatoprotective effect of leaves of MorindatinctoriaRoxb. against acetaminophen induced liver damage in rats. Drug Invention Today. 2013 Sep; (3):223-8. doi: 10.1016/j.dit.2013.06.008. 
13. Yasojima EY, Teixeira RKC, HouatAP, Costa FLS, Silveira EL, Brito MVH, Lopes Filho GJ. Effect of copaiba oil on correction of abdominal wall defect treated with the use of polypropylene/ polyglecaprone mesh. Acta Cir Bras. 2013 Fev;28(2):131-5. doi: 10.1590/S0102-86502013000200008.

14. Guimarães-Santos A, Santos DS, Santos IR, Lima RR, Pereira A, de Moura LS, Carvalho RN Jr, Lameira O, Gomes-Leal W. Copaiba oil-resin treatment is neuroprotective and reduces neutrophil recruitment and microglia activation after motor cortex excitotoxic injury. Evid Based Complement Alternat Med. 2012;2012:918174. doi:10.1155/2012/918174.

15. Noguchi A, Reis JMC, Dias CS, Epaminondas WA, Azevedo PSR, Brito MVH. Níveis séricos de aminotransferases, bilirrubinas e gama-glutamiltranspeptidase após a administração de óleo de copaíba em ratos. Acta Cir Bras. 2002 Mar;17(2):130-4. doi: $10.1590 / \mathrm{S} 0102-86502002000200008$.

16. Teixeira RKC, Yamaki NV, Yasojima EY, Brito MVH. Effect of copaiba oil in hepatic damage induced by acetaminophen in rats. Acta Cir Bras. 2013 July;28(7):526-30. doi: 10.1590/S010286502013000700008 .

17. Enescu A, Mitrut P, Buteicã E, Stãnoiu B, Enescu A. Drug-induced hepatitis - morphological and ultrastructural aspects. Rom J Morphol Embryol. 2007 Dec;48(4):449-54. PMID: 18060200.

18. Hinson JA, Roberts DW, James LP. Mechanisms of acetaminopheninduced liver necrosis. Handb Exp Pharmacol. 2010;196:369-405. doi: 10.1007/978-3-642-00663-0 12.

19. Brito NMB, Kulay Júnior L, Simões MJ, Damous SHB, Lamarão LG. O óleo de milho como substância controle no colo uterino de ratas. Rev An Med UFPE. 2000 Jan;45(1):32-5.

20. Melo JUS, Santos JMV, Kimura OS, Campos Júnior MM, Melo RB, Vasconcelos PRL. Efeitos dos ácidos graxos sobre a regeneração hepática em ratos. Rev Col Bras Cir. 2010 Sep;37(5):351-7. doi: 10.1590/S0100-69912010000500008.
21. Botelho NM, Carvalho RKV, Matos LTMB, Lobato RC, Correa SC. Efeito subagudo de altas doses do óleo de copaíba nos níveis de enzimas hepáticas em soro de ratos. Rev Para Med. 2010 Dec;24(3/4):51-6.

22. Botelho NM, Carvalho RKV,Matos LTMB, Correa SC, Lobato RC, Brito RB. Estudo morfológico do efeito subagudo de altas doses do óleo de copaíba em ratos. Rev Para Med. 2011 Jan;25(1):9-14.

\section{Correspondence:}

Marcus Vinicius Henriques Brito

Rua Apinagés, 630/202

66.033-170 Belém - PA Brasil

Tel.: (55 91)3222-9752/8854-8895

marcusvhbrito@gmail.com

Received: Aug 11, 2014

Review: Sep 12, 2014

Accepted: Oct 13, 2014

Conflict of interest: none

Financial source: Institutional Program for Scientific Initiation Scholarship (PIBIC), National Council for Scientific and Technological Development $(\mathrm{CNPq})$

${ }^{1}$ Research performed at Experimental Surgery Laboratory, School of Medicine, State University of Para (UEPA), Belem-PA, Brazil. 